\title{
Thulium laser vaporesection (ThuVaRP) versus bipolar transurethral resection of the prostate (TURP) in benign prostate hyperplasia in term of safety and efficacy: A two-year-follow-up study in Erbil, Iraq
}

\begin{tabular}{ccc}
\hline Wishyar Jamal Al-Bazzaz $^{1 *}$ & Nihad Rifaat Jawad $^{2}$ & Ali W. AlKhayat $^{3}$ \\
\hline & Abstract
\end{tabular}

Background and objective: Prostate Thulium laser vaporization is a novel treatment option for a bladder outlet obstruction caused by benign prostate enlargement. However, this surgical technique has not yet been standardized. We present our finding of using Tm vaporesection of the prostate. This study aimed to assess the efficacy and safety of thulium laser versus bipolar transurethral resection of the prostate for treating patients with benign prostatic obstruction.

Methods: Sixty three consecutive patients with benign prostatic hyperplasia attending public and private clinics in Erbil city were included in a comparative study from June 2014 to July 2016. Thulium laser vaporesection of the prostate was done for Group I $(n=31)$, and transurethral resection of the prostate was done for Group II $(n=32)$. All cases were evaluated preoperatively and were evaluated at 6-24 months postoperatively by international prostate symptom score, post void residual urine volume, and quality of life. Forty four patients completed the two years of follow up.

Results: Thulium laser vaporization was significantly superior to bipolar plasmakinetic resection of the prostate in term of catheterization time (1.2 \pm 0.7 vs $4.9 \pm 1.7$ days, $P \leq 0.001)$, hospital stay $(1.5 \pm 0.9$ days vs $3.2 \pm 1.6$ days, $P=0.001)$ and drop in hemoglobin $(0.8 \pm 0.3$ vs $2.35 \pm 0.4 \mathrm{~g} / \mathrm{dl}, P \leq 0.001)$ and inferior to PKRP operation time $(68.2 \pm 27.3$ vs $58.3 \pm 22.7, P=0.122)$. Both groups resulted in a significant improvement from baseline in terms of subjective symptoms scoring, but no significant difference was found between the two groups.

Conclusion: Thulium laser vaporesection of the prostate is a safe and effective procedure for the treatment of symptomatic benign prostatic obstruction, with low perioperative morbidity however, both procedures showed no significant difference in terms of international prostate symptom score, post void residual urine volume and quality of life.

Keywords: Benign prostatic hyperplasia; Transurethral resection of the prostate; Thulium laser.

\section{Introduction}

Benign prostatic hyperplasia (BPH) is one of the most common diseases in middle aged and elderly men, and is one of the most common causes of lower urinary tract symptoms (LUTS), ${ }^{1}$ and can significantly affect the quality of life (QoL) of a patient and also lead to more severe complications, such as acute urinary retention (AUR), recurrent urinary tract infection (UTI), hematuria, and dysfunction of kidney. ${ }^{2}$ Transurethral resection of the prostate (TURP) is still considered the gold standard of surgical treatment of benign prostatic obstruction (BPO) due to benign prostatic hyperplasia $(\mathrm{BPH}){ }^{3}$ However, it is associated with considerable perioperative and postoperative morbidity, such as transurethral resection syndrome (TURS), bleeding, and prolonged recovery. ${ }^{4}$ In recent years to overcome these known pitfalls, various surgical laser

${ }_{1}^{1}$ Department of Urology, Rizgary Teaching Hospital, Erbil, Iraq.

2 Department of Surgery, College of Medicine, Hawler Medical University, Erbil, Iraq.

${ }^{3}$ Erbil Teaching Hospital, Erbil, Iraq.

* Correspondence: dr.wishyaralbazzaz@gmail.com 
procedures have been introduced to clinical practice as a replacement for TURP. Published improvement of laser therapy over traditional TURP include less risk of TUR syndrome, ${ }^{5}$ lower blood loss ${ }^{6}$ and ability to treat larger glands. ${ }^{7}$ The thulium laser is a new surgical laser with a tunable wavelength of between 1.75 and 2.22 (micrometer). It may have several advantages over holmium laser, including improved spatial beam quality, more precise tissue incision, and operation in continuous-wave pulsed modes. ${ }^{8}$ Thulium laser has been capable of rapid vaporization and coagulation of prostatic tissue, ${ }^{9}$ whereas cutting and ablation characters are excellent at $100-W$ energy level. Therefore a thulium laser producer called thulium laser resection of prostate-tangerine technique (TmLRPTT). ${ }^{10}$ Currently, the maximum power has been improved to $120 \mathrm{~W}$, and theoretically, a mean total of $1.08 \mathrm{gr}$ of tissue vaporization per minute. ${ }^{11}$ Several techniques have been described for application of the thulium laser in prostate surgery: vaporization (ThuVap), vaporesection (ThuVaRP), vaponucleation (ThuVEP), and enucleation (ThuLEP). ${ }^{12}$ This study aimed to assess the efficacy and safety of thulium laser versus bipolar transurethral resection of the prostate for treating patients with benign prostatic obstruction.

\section{Methods}

\section{Patients}

From June 2014 to July 2016, 63 BPH patients received surgical treatment with either ThuVaRP (31 in group I) or TURP (32 in group II) at the urology department in Rizgary teaching hospital, in addition to two private hospitals (Soran and Sardam hospitals in Erbil-Kurdistan-Iraq). All participants had given informed consent before their inclusion in this study, Inclusion criteria were males aged 50 years and more, failure of medical therapy, an international prostate system score (IPSS) $>7$, normal level of age-specific prostate specific antigen (PSA), transabdominal ultrasound prostate volume $<70 \mathrm{ml}$, and post void residual urine volume (PRV) $<150 \mathrm{ml}$. Exclusion criteria were prostate volume $<30 \mathrm{ml}$, documented or suspected prostate cancer, neurogenic bladder, bladder stone or diverticula and urethral stricture. All patients were evaluated preoperatively by scoring subjective symptoms with international prostate symptom score (IPSS) and quality of life score (QoLS), a physical examination with digital rectal examination (DRE), laboratory analysis with total serum prostate-specific antigen (T.PSA), transabdominal ultrasound measurement of prostate volume and PVR urine volume.

\section{Equipment and techniques.}

Patients were sent to the operating room and put in a dorsal lithotomy position with legs supported in stirrups with minimal flex at the hips. The procedure was performed under general or spinal anesthesia. Thulium lasers with an average power of 100 W (LISA laser products OHG, Germany), operating in continuous wave mode, were used for this procedure. The energy was delivered by way of 550 micrometer end firing percuFib fibers. The laser fibers were introduced using Karl Storz 26F continuous-flow resectoscope. Irrigation with saline was used in all procedures. The cutting section was 160 $W$, and the coagulation power setting was $80 \mathrm{w}$. The TURP operations were performed with a bipolar system using Karl Storz continuous-flow resectoscope. At the end of both groups' procedures, a standard $22 \mathrm{~F}$ three-way catheter was inserted and connected to straight drainage. Bladder irrigation with normal saline $9 \%$ solution was necessary until hematuria was sufficiently resolved. For both groups, $1 \mathrm{gm}$ ceftriaxone intravenously used 1 hour before the operation and in 5 postoperative days (once a day).

\section{Assessment and follow up}

Perioperative outcomes, including operation time, decrease in hemoglobin, irrigation volume, postoperative 
catheterization time, hospital stay, and complications were recorded. The postoperative urinary parameters, including IPSS, PVR urine volume, and QoLS were evaluated at 6 months, one year, and two years.

\section{Statistical analysis}

Data had been analyzed using the website calculator: OpenEpi.com. Student's test was used to compare two means. The Chi-square test (or Fisher's exact test) was used to compare proportions. A $P$ value of $\leq 0.001$ was considered statistically significant.

\section{Results}

As shown in Table 1, the baseline characteristic in the two groups were comparable with regard to patient age, IPSS, PSA level, prostate volume, PVR urine volume, and QoLS. The perioperative data are listed in Table 2. The procedures were successfully performed in all patients. Compared with TURP, ThuVaRP required longer operation time $(68.2 \pm 27.3$ vs. 58.3 \pm 22.7 min., $P=0.122$ ) but resulted in less hemoglobin decrease than TURP $(0.8 \pm 0.3$ vs. $2.35 \pm 04 \mathrm{gr} / \mathrm{l}, P<0.001)$ demonstrating the relative lower volume of blood loss. ThuVaRP also needed shorter catheterization time $(1.2 \pm 0.7$ vs. $4.9 \pm 1.7$ day, $P<0.001$, less irrigation volume (12.11 \pm 1.7 vs. $26.6 \pm 3.9$ L, $P<0.001$, and shorter hospital length of stay $(1.5 \pm 09$ vs. $3.2 \pm 1.6$ days, $P<0.001)$. Postoperative two years follow up; No patient was lost during the first six months follow-up. A total of 44 patients completed the two years follow-up, 21 from the ThuVaRP group, and 23 from the TURP group.

Table 1: Patients' characteristics and preoperative values of two groups.

\begin{tabular}{lccc}
\hline Parameters & TURP Group $(\mathbf{n}=\mathbf{3 2})$ & ThuVaRP group $(\mathbf{n}=\mathbf{3 1})$ & $\boldsymbol{P}$ value \\
\hline Age, years & $67.8 \pm 6.6(53-87)$ & $68.7 \pm 6.3(51-87)$ & 0.582 \\
IPSS & $20.7 \pm 6.6(11-35)$ & $20.3 \pm 6.7(11-35)$ & 0.812 \\
PSA, mg/mI & $2.25 \pm 1.31(0.22-4.08)$ & $2.2 \pm 1.31(0.21-4.03)$ & 0.880 \\
TAU, Prostate volume, & $51.1 \pm 12.2(40.1-73.2)$ & $55.3 \pm 12.7(41.2-74.1)$ & 0.185 \\
ml & $70.1 \pm 29.3(48-145)$ & $72.7 \pm 30.2(50-140)$ & 0.729 \\
PVR urine volume & $4.7 \pm 0.9(3-6)$ & $4.5 \pm 1.1(3-6)$ & 0.432 \\
QoLS & &
\end{tabular}

IPSS international prostate symptom score, PSA prostate specific antigen, PVR postvoidal residual, SD standard deviation, QoLS Quality of Life Style.

Table 2: Perioperative data.

\begin{tabular}{lccc}
\hline Parameters & TURP group $(\mathbf{n}=\mathbf{3 2})$ & ThuVaRP group $(\mathbf{n}=\mathbf{3 1})$ & $\boldsymbol{P}$ value \\
\hline Operation time, min & $58.3 \pm 22.7(47-85)$ & $68.2 \pm 27.3(55-104)$ & 0.122 \\
Hemoglobin, decrease, $\mathbf{g} / \mathbf{L}$ & $2.35 \pm 0.4(1.2-3.0)$ & $0.8 \pm 0.3(0.2-1.3)$ & $<0.001$ \\
Irrigated volume, $\mathrm{L}$ & $26.6 \pm 4.9(7-30)$ & $12.1 \pm 7.7(6-21)$ & $<0.001$ \\
Catheterization, days & $4.9 \pm 1.7(5-7)$ & $1.2 \pm 0.7(0.5-2)$ & $<0.001$ \\
Hospital stay, days & $3.2 \pm 1.6(3-5)$ & $1.5 \pm 0.9(1-3)$ & $<0.001$ \\
\hline The values were assayed of the beginning of the operation and 1 hour postoperative &
\end{tabular}


Three patients died from other diseases unrelated to LUTS, and 16 patients were lost to follow up. The follow-up parameters are shown in Table 3. There were significant improvements of both groups in IPSS, PVR urine volume, and QoLS of two years follow up compared with the preoperative parameters. However, at six months, one and two years postoperatively, improvement in these parameters between TURP and ThuVaRP groups showed no significant difference. The mean IPSS score decreased from $20.7 \pm 6.6$ and $20.3 \pm 6.7$ at baseline to $6.2 \pm 2.6$ and $6.7 \pm 3.0$ respectively $(P=0.556)$ the mean PVR urine volume decreased from $70.1 \pm 29.3$ and $72.7 \pm 30.2$ to $33.8 \pm 19.2$ and $34.1 \pm 16$ respectively $(P=0.956)$ and the mean QoLS decreased from $4.7 \pm 0.9$ and $4.5 \pm 1.1$ to $1.5 \pm 1.0$ and $1.4 \pm 0.9$, respectively $(P=0.730)$. Perioperatively along with six months, one year and two years follow up was carried on to assess events and complications shown in Table 4. No blood transfusion was needed in the ThuVaRP group; however, three patients needed it in TURP group. TUR syndrome occurred in one ThuVaRP patient and three TURP patients. Urinary retention caused by clot occurred in one TURP patients and no in ThuVaRP patient. Urethral stricture occurred in one ThuVaRP patient and two TURP patients.

Table 3: Postoperative follow up.

\begin{tabular}{|c|c|c|c|}
\hline \multicolumn{4}{|c|}{ Mean + SD (range) at 6 months } \\
\hline Parameters & TURP (n=32) & ThuVaRP $(n=31)$ & $P$ value \\
\hline IPSS & $4.7 \pm 1.6(1-10)$ & $5.1 \pm 1.8(1-12)$ & 0.354 \\
\hline PVR urine volume, $\mathrm{ml}$ & $27.8 \pm 13.0(0-55)$ & $28.1 \pm 13.3(0-58)$ & 0.928 \\
\hline QoLS & $1.1 \pm 0.8(1-5)$ & $1.2 \pm 0.9(1-5)$ & 0.642 \\
\hline \multicolumn{4}{|c|}{ Mean \pm SD (range) at 1 year } \\
\hline Parameters & TURP (n=28) & ThuVaRP $(n=31)$ & $P$ value \\
\hline IPSS & $5.3 \pm 2.2(1-12)$ & $5.9 \pm 2.0(1-12)$ & 0.300 \\
\hline PVR urine volume, $\mathrm{ml}$ & $25 \pm 15.6(0-60)$ & $25.6 \pm 12.6(0-62)$ & $<0.001$ \\
\hline QoLS & $1.3 \pm 0.7(1-4)$ & $1.3 \pm 0.6(1-4)$ & $>0.999$ \\
\hline \multicolumn{4}{|c|}{ Mean \pm SD (range) at 2 years } \\
\hline & TURP $(n=23)$ & ThuVaRP $(n=21)$ & $P$ value \\
\hline IPSS & $6.2 \pm 2.6(1-12)$ & $6.7 \pm 3.0(1-12)$ & 0.556 \\
\hline PVR urine volume, $\mathrm{ml}$ & $33.8 \pm 19.2(0-64)$ & $34.1 \pm 16.4(0-63)$ & 0.956 \\
\hline QoLS & $1.5 \pm 1.0(1-3)$ & $1.4 \pm 0.9(1-4)$ & 0.730 \\
\hline
\end{tabular}

PVR post-voiding residual, IPSS international prostate system score, QoLS quality of life score

Table 4: Adverse events and complications.

\begin{tabular}{lccc}
\hline Perioperative \& first follow up & $\begin{array}{c}\text { TURP } \\
\text { No. (\%) }\end{array}$ & $\begin{array}{c}\text { ThuVaRP } \\
\text { No. (\%) }\end{array}$ & $\boldsymbol{P}$ value \\
\hline Perioperative \& first follow up & $\mathbf{N = 3 2}$ & $\mathbf{N}=\mathbf{3 1}$ & 0.238 \\
Blood transfusions & $3(9.3 \%)$ & $0(0.0 \%)$ & 0.492 \\
TUR syndrome & $2(6.25)$ & $0(0.0 \%)$ & 0.707 \\
Urinary tract infection & $5(15.62 \%)$ & $3(9.67 \%)$ & $>0.999$ \\
Re-Catheterization & $1(3.3 .12)$ & $0(0.0 \%)$ & 0.671 \\
Transitory urge incontinence & $4(12.5 \%)$ & $2(6.45 \%)$ & $\mathbf{N}=\mathbf{2 1}$ \\
12-24 months postoperative complications & $\mathbf{N = 2 3}$ & $11 / 21(52.38 \%)$ & 0.989 \\
Retrograde ejaculation & $12(52.17 \%)$ & $0(0.0 \%)$ & $>0.999$ \\
Stress incontinence & $1(4.34 \%)$ & $1(4.76 \%)$ & 0.489 \\
Urethral stricture & $2(8.69 \%)$ & & \\
\hline ThuVaRP, thulium laser vaporization, TURP, transurethral resection of prostate. & &
\end{tabular}




\section{Discussion}

Although being the gold standard for treating $\mathrm{BPH}$, major drawback of contemporary monopolar TURP remain to be intraoperative and preoperative complications. The most relevant complications included bleeding that required blood transfusion $(2 \%$; range, $0-9 \%)$, TURPS $(0.8 \%$; range, $0-5 \%)$, acute urinary retention (4.5\%; range, $0-13.3 \%)$, clot retention (4.9\%; range, 0-39\%), and urinary tract infection $(4.1 \%$; range, 0 $22 \%) .{ }^{13}$ Modern urology faces tremendous competition between various modalities in $\mathrm{BPH}$ endoscopic treatment in a race for minimal invasiveness, reduced complications, and long-term efficacy. The bipolar TURP, in general, was described as potentially permitting a longer resection time and providing improved hemostasis, thus enabling the surgeon to resect larger prostates without compromising safety. ${ }^{14}$ The thulium laser, a new type of surgical laser that has recently been applied in urology and appears to solve many of the limitations of both these devices, has been commonly used in recent decades. The center wavelength of the laser is tunable between 1.75 and 2.22 micrometers allowing the wavelength to exactly match 1.92 micrometers water absorption peak in tissue. The high density of absorbed energy at the tissue surface leads to instant vaporization and limits the penetration depth from 500 to 2000 micrometers, which covers minimum and maximum microvessel diameters of hyperplastic prostate, ${ }^{15}$ thus resulting in sufficient hemostasis with minimal thermal injury to surrounding tissue. In our study, bipolar TURP provides the subjective advantages of remarkable intraoperative visibility caused by a smooth wound surface, reduced bleeding, and detailed visual differentiation of adenomatous tissue and fibers of the prostatic capsule after resection. With ThuVaRP, nearly no bleeding is visualized during the operation, and it provides better intraoperative visibility, although leaving a rough surface and a sharp margin on the vaporization area. The superior coagulation obtained during ThuVaRP lead to a significantly lower mean hemoglobin drop than during PKRP $(0.8 \pm 0.3$ vs. $2.35 \pm 0.4 \mathrm{~g} / \mathrm{L}, P<0.001)$. Furthermore as assessed by the better coagulation, patients receiving ThuVaRP also needed shorter catheterization duration $(1.2 \pm 07$ vs. $4.9 \pm 1.7$ days, $P<0.001)$, less irrigation volume $(12.1 \pm 7.7$ vs. $26.6 \pm 4.9 \mathrm{~L}, P<0.001)$, and shorter hospital stay $(1.5 \pm 0.9$ vs. $3.2 \pm 1.6$ days, $P<0.001)$, compared with a 550 micrometer end firing fiber of ThuLEP, the standard resection loop of bipolar TURP provided higher resecting efficacy and resulted in shorter operation time (58.3 \pm 22.7 vs. $68.2 \pm 27.3 \mathrm{~min}, P=0.122)$. The incidence of TUR syndrome was $6.25 \%$ among the TURP group, while none of the ThuVaRP groups developed such a complication, knowing that saline was used as an irrigation solution for the TURP group and glycine was used for ThuVaRP group. No patients were lost during the six months follow up, and procedures obtained comparable results in the postoperative urinary parameters of IPSS, PVR urine volume, and QoLS at the intervals of six months, one year and two years. As for the longer follow up, although some patients lost each year, there was no difference in these parameters between the two procedures. So, a definite conclusion is not available. Compared with the PKRP series performed by Hu et al., ${ }^{16}$ an operation time of $36.4 \mathrm{~min}$ a hospital stay of 4.2 days, the mean PVR urine volume decreases from 126.33 to $10.45 \mathrm{~mL}$, the mean IPSS score decreases from 15.79 to 7.51 , and the mean QoL score decrease from 4.36 to 1.91, respectively, in our study, including both bipolar TURP and ThuVaRP, required more operation time (58.3 and $68.2 \mathrm{~min}$, respectively), less hospital stay (3.2 and 1.5 days, respectively), mildly larger PVR urine volume (33.8 And $34.1 \mathrm{ml}$ and lower IPSS (6.2 and 6.7), these differences might partly be caused by the different surgical procedures and perioperative 
parameters. Compared with ThuVaRP series performed by Xia et al., ${ }^{12}$ and operation time of $43.7 \mathrm{~min}$, a hemoglobin decreases of $0.9 \mathrm{~g} / \mathrm{DI}$, and hospital stay of 4.9 days, in our series, including both bipolar TURP and ThuLEP, no significant difference was seen in perioperative parameters (PVR urine volume, IPSS, and QoLS) and postoperative parameter in both series.

\section{Conclusion}

Bipolar TURP and ThuVaRP are both safe and efficient procedures for treating patients with symptomatic BPH. Compared with bipolar TURP, ThuVaRP offers advantages in intraoperative safety, minimal blood loss, less irrigation, shorter catheterization, and shorter hospital stay but needs a longer operation time. Assessment at mid and long-term follows up showed no difference in urinary parameters.

\section{Competing interests}

The authors declare no competing interests.

\section{References}

1. Oelke M, Bachmann A, Descazeaud A, Emberton M, Graves S, Michel MC, et al. EAU Guidelines on the treatment and follow-up of non-neurogenic male lower urinary tract symptoms including benign prostatic obstruction. Euro Urol 2013; 64:118-40.

2. Zhuo J, Wei HB, Zhao FJ, Sun F, Han BM, Sun XW, et al. Two-micrometer thulium laser resection of the prostate-tangerine technique for patients with acute urinary retention. Lasers Med Sci 2014; 29(3):1093-98.

3. Madersbacher S, Alivizatos G, Nordling J, Sanz CR, Emberton M, de la Rosette JJ. EAU 2004 guidelines on assessment, therapy and follow-up of men with lower urinary tract symptoms suggestive of benign prostatic obstruction (BPH guidelines). Eur Urol 2004; 46:547-54.

4. Reich O, Gratzke C, Bachmann A, Seitz M, Schlenker B, Hermanek $P$, et al.Urology section of the Bavarian Working Groub for Quality Assurance. Morbidity, mortality and early outcome of transurethral resection of the prostate: a postoperative multicenter evaluation of 10,654 patients. J Urol 2008; 180:246-9.

5. Al-Ansari A, Younes N, Sampige VP, Al-Rumaihi K, Ghafouri A, Gul T, et al. Green light laser vaporization versus transurethral resection of HPS 120-W the prostate for treatment of benign prostatic hyperplasia: a randomized clinical trial with midterm follow-up. Eur Urol 2010; 58(3):349 -55 .

6. Barboza LE, Malafaia O, Slongo LE, Meyer F, Nassif PA, Tabushi FI. Holmium laser enucleation of the prostate. (HoLEP) versus transurethral resection of the prostate. (TURP). Rev Col Bras Cir 2015; 42:165-70.

7. Dusing MW, Krambeck AE, Terry C, Matlaga BR, Miller NL, Humphreys MR. Holmium laser enucleation of the prostate: efficiency gained by experience and operative technique. J Urol 2010; 184:635-40.

8. Fried NM, Murray KE. High-power thulium fiber laser ablation of urinary tissues at $1.94 \mathrm{um}$. J Endourol 2005; 19:25-31.

9. Fried NM. High-power laser vaporization of the canine prostate using a $110 \mathrm{~W}$ thulium fiber laser at $1.91 \mathrm{pm}$. Lasers Surg Med 2005; 36:52-6.

10. Xia SJ, Zhang YN, Lu J, Sun XW, Zhang J, Zhu YY, et al. Thulium laser resection of prostate -tangerine technique in treatment of benign prostate hyperplasia in Chinese. Zhonghua Yi Xue Za Zhi 2005; 85:3225-8.

11. Xia SJ, Zhuo J, Sun XW, Han BM, Shao $Y$, Zhang YN. Thulium laser versus standard transurethral resection of the prostate: A Randomized Prospective trial. Eur Urol 2008; 53(2):382-9.

12. Bach T, Xia SJ, Yang Y, Mattioli S, Watson GM, Gross AJ, et al. Thulium: YAG $2 \mathrm{Im} \mathrm{cW}$ laser prostatectomy: where do we stand? World J Urol 2010; 28(2):163-8.

13. Cornu JN, Ahyai S, Bachmann A, de la Rosette J, Gilling P, Gratzke C, et al. A systematic 13 review and meta-analysis of functional outcomes and complications following transurethral procedures for lower urinary tract symptoms resulting from benign prostatic obstruction: an update. Eur Urol 2015; 67:1066-96.

14. Reich O. Bipolar transurethral resection of the prostate: what did we learn, and where do we go from here? Eur Urol 2009; 56(5):796-7.

15. Huang $\mathrm{X}$, Wang $\mathrm{XH}$, Wang $\mathrm{HP}$, Qu LJ. Comparison of the microvessel diameter of hyperplastic prostate and the coagulation depth achieved with mono- and bipolar transurethral resection of the prostate. A pilot study on hemostatic capability. Scand J Urol Nephrol 2008; 42:265-8.

16. Hu Y, Dong X, Wang G, Huang J, Liu M, Peng B. Five-year follow-up study of transurethral plasmakinetic resection of the prostate for benign prostatic hyperplasia. J Endourol 2016; 30:97101. 